\title{
Optimizing Synthetic Process of Epoxysuccinic Acid
}

\author{
Zhenfa Liu ${ }^{1,2, a}$, Haihua Li $i^{1,2, b}$, Yuhua Gao ${ }^{1,2, c}$, Lihui Zhang ${ }^{1,2, d}$ \\ ${ }^{1}$ Institute of Energy Resources, Hebei Academy of Sciences Shijiazhuang, China \\ ${ }^{2}$ Hebei Engineering Research Center for Water Saving in Industry \\ aemail: Izf63@sohu.com, bemail: c.t.0205@sina.com, email: gaoyuhua77@163.com, demail: \\ zlhkxy@sohu.com
}

Keywords: epoxysuccinic acid; composite catalyst; synthesis

\begin{abstract}
Epoxysuccinic acid (ESA) was synthesized using maleic anhydride (MA) as the raw material, $\mathrm{NaOH}$ as the initiator and $30 \% \mathrm{H}_{2} \mathrm{O}_{2}$ as the oxidizing agent, and three kinds of agents as catalysts, and the effects of different catalysts on the yield of ESA were investigated. The results showed that the optimal composite catalyst was composed of sodium tungstate $\left(\mathrm{Na}_{2} \mathrm{WO}_{4}\right)$ and sodium molybdate $\left(\mathrm{Na}_{2} \mathrm{MoO}_{4}\right)$. The optimal synthetic conditions of ESA were as follows: the molar ratio of $\mathrm{MA}$ to $\mathrm{NaOH}$ was $1: 2$, the mass ratio of $30 \% \mathrm{H}_{2} \mathrm{O}_{2}$ to MA was $7: 10$, the epoxidation temperature and time were $65^{\circ} \mathrm{C}$ and $0.5 \mathrm{~h}$, and the dosage of the catalyst was $4 \%$ of MA. Under the optimal synthetic condition, the yield of ESA can reach $95.68 \%$. The structure of ESA was characterized by Fourier transform infrared spectrometry (FT-IR).
\end{abstract}

\section{Introduction}

Polyepoxysuccinic acid (PESA) is originally developed as a scale and corrosion inhibitor. It has strong chelating ability for calcium ion, magnesium ion and iron ion, which makes it suitable for water treatment with high hardness and high alkalinity, and PESA without phosphorus and nitrogen is recognized as a green water treatment agent [1-5]. Epoxysuccinic acid (ESA) is the intermediate product in the synthesis of PESA [6-9]. Its yield has a great influence on the yield, the cost, and the performance of PESA. Thus, the research about the optimal synthetic condition of ESA was meaningful.

In this research, sodium tungstate $\left(\mathrm{Na}_{2} \mathrm{WO}_{4}\right)$, sodium molybdate $\left(\mathrm{Na}_{2} \mathrm{MoO}_{4}\right)$ and sodium vanadate $\left(\mathrm{Na}_{3} \mathrm{VO}_{4}\right)$ were investigated as catalysts for the synthesis of ESA. Synthesis conditions such as molar ratio of MA to $\mathrm{NaOH}$, reaction temperature and time were investigated to obtain the higher yield of ESA. The structure of the product was characterized by FT-IR.

\section{Experimental}

Agents and instrument

Agents used in the present research included the analytical grade $\mathrm{NaOH}, \mathrm{H}_{2} \mathrm{O}_{2}, \mathrm{Na}_{2} \mathrm{WO}_{4}$, $\mathrm{Na}_{2} \mathrm{MoO}_{4}$, and $\mathrm{Na}_{3} \mathrm{VO}_{4}$, and the technical grade maleic anhydride (MA).

The instrument used in the present research was Fourier transform infrared spectrometry (USA, Perkin-Elmer, Spectrum 100).

\section{Synthesis of ESA}

$24.5 \mathrm{~g}$ MA and $40 \mathrm{~mL}$ deionized water were added into a four-neck round bottom flask with stirring at normal temperature till the solution completely transparent. $0.5 \mathrm{~mol} \mathrm{NaOH}$ dissolved in $50 \mathrm{~mL}$ distilled water (the molar rate of $\mathrm{MA}$ to $\mathrm{NaOH}$ was 1:2) was slowly dropped into the solution below $55{ }^{\circ} \mathrm{C}$. Then the solution was heated to $55{ }^{\circ} \mathrm{C}, 0.5 \mathrm{~g}$ catalyst was dissolved in the solution. Three kinds of compound agents were used in the experiments. The numbers and the compositions of the catalysts were listed in table 1 . For convenience, the catalyst was represented by the number in table 1 in the post text. 
Table 1 Numbers and compositions of the catalysts

\begin{tabular}{|c|c|c|c|}
\hline Number & $1^{\#}$ & $2^{\#}$ & $3^{\#}$ \\
\hline Composition & $\mathrm{Na}_{2} \mathrm{WO}_{4}$ & $\mathrm{Na}_{2} \mathrm{WO}_{4}+\mathrm{Na}_{2} \mathrm{MoO}_{4}$ & $\mathrm{Na}_{2} \mathrm{WO}_{4}+\mathrm{Na}_{2} \mathrm{MoO}_{4}+\mathrm{Na}_{3} \mathrm{VO}_{4}$ \\
\hline Mass ratio & $/$ & $1: 1$ & $2: 1: 1$ \\
\hline
\end{tabular}

Then $10 \mathrm{~mL} 30 \% \mathrm{H}_{2} \mathrm{O}_{2}$ was added in the solution in $0.5 \mathrm{~h}$ and then the solution was heated at $65{ }^{\circ} \mathrm{C}$ for $0.5 \mathrm{~h}$. After the reaction was finished, the light yellow solution was obtained, which was the target produce of ESA. The synthesis route of ESA is given in scheme 1.

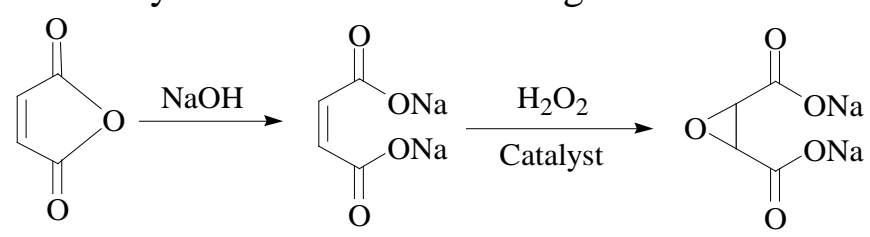

Scheme 1. Synthesis route of ESA.

Measurement of the yield of ESA [9]

The epoxy group in ESA molecule can react with $\mathrm{HCl}$ to generate chlorinated alcohol with $\mathrm{MgCl}_{2}$ saturated solution. After the reaction, the rest of $\mathrm{HCl}$ was titrated by $\mathrm{NaOH}$ standard solution. The yield of ESA was calculated according to equation (1).

$$
X=\frac{\left[V_{0}-\left(V_{1}-V_{2} \times m\right)\right] \times C \times M}{10 \times m} \times 100 \%
$$

Where $V_{0}(\mathrm{~mL})$ is the consumption of $\mathrm{NaOH}$ standard solution volume for the blank sample; $V_{1}$ $(\mathrm{mL})$ is the consumption of $\mathrm{NaOH}$ standard solution volume for the sample with $\mathrm{MgCl}_{2}$ at $60{ }^{\circ} \mathrm{C}$ for $0.75 \mathrm{~h} ; C(\mathrm{~mol} / \mathrm{L})$ is the concentration of $\mathrm{NaOH}$ standard solution; $m(\mathrm{~g})$ is the mass of the sample; $V_{2}(\mathrm{~mL})$ is the consumption of $\mathrm{NaOH}$ standard solution volume for per gram sample with $\mathrm{MgCl}_{2}$ at normal temperature for $0.75 \mathrm{~h} ; M(\mathrm{~mol} / \mathrm{g})$ is the molecular weight of ESA.

\section{Results and discussion}

Effect of the mole ratio of MA to $\mathrm{NaOH}$ on the yield of ESA

The synthetic conditions of ESA were as follows: the contant of $\mathrm{H}_{2} \mathrm{O}_{2}$ was $50 \%(\mathrm{w} / \mathrm{w})$, the epoxidation temperature was $65^{\circ} \mathrm{C}$, the epoxidation time was $2 \mathrm{~h}$, and the contant of the composite catalyst was $2 \%(\mathrm{w} / \mathrm{w})$. Fig.1 shows the effect of the molar ratio of $\mathrm{MA}$ to $\mathrm{NaOH}$ on the yield of ESA with different composit catalysts. As shown in Fig.2, the yield of ESA was the maximum when the molar ratio of $\mathrm{MA}$ to $\mathrm{NaOH}$ was 1:2. It was because when the molar ratio of MA to $\mathrm{NaOH}$ was less than 1:2, the ESA was hydrolyzed to tartaric acid at the acid environment, while that was larger than 1:2, $\mathrm{H}_{2} \mathrm{O}_{2}$ decomposed with the dosage of $\mathrm{NaOH}$ increasing. 


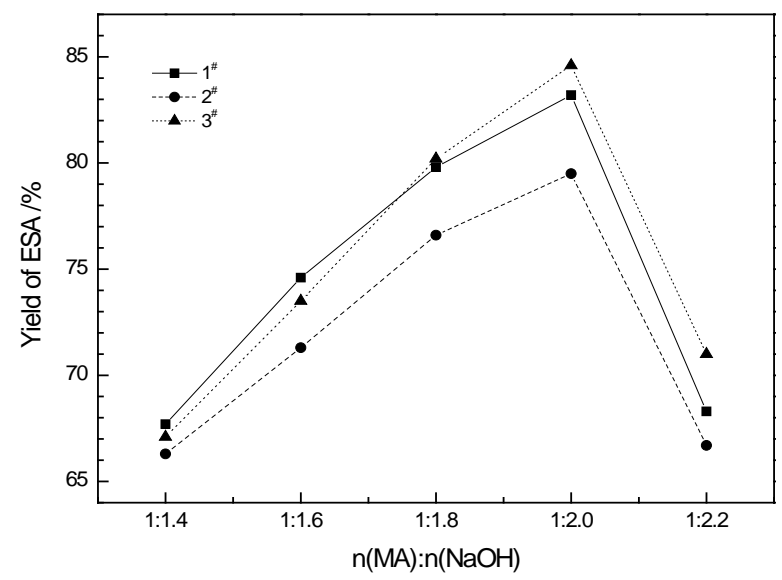

Fig.1. Influence of the mole ratio of $\mathrm{MA}$ to $\mathrm{NaOH}$ on the yield of ESA

Effect of $\mathrm{H}_{2} \mathrm{O}_{2}$ dosage on the yield of ESA

The synthetic conditions of ESA were as follows: the molar ratio of MA to $\mathrm{NaOH}$ was 1:2, the epoxidation temperature was $65{ }^{\circ} \mathrm{C}$, the epoxidation time was $2 \mathrm{~h}$, and the contant of the composite catalyst was $2 \%(\mathrm{w} / \mathrm{w})$. Fig.2 shows the effect of $\mathrm{H}_{2} \mathrm{O}_{2}$ dosage on the yield of ESA with different composit catalysts. The optimal dosages of $\mathrm{H}_{2} \mathrm{O}_{2}$ were $90 \%(\mathrm{w} / \mathrm{w}), 70 \%(\mathrm{w} / \mathrm{w})$ and $50 \%(\mathrm{w} / \mathrm{w})$, respectively, for $\mathrm{Na}_{2} \mathrm{WO}_{4}$, the compound of $\mathrm{Na}_{2} \mathrm{WO}_{4}$ and $\mathrm{Na}_{2} \mathrm{MoO}_{4}$, and the compound of $\mathrm{Na}_{2} \mathrm{WO}_{4}, \quad \mathrm{Na}_{2} \mathrm{MoO}_{4}$ and $\mathrm{Na}_{3} \mathrm{VO}_{4}$ used as the catalysts. When the dosage of $\mathrm{H}_{2} \mathrm{O}_{2}$ was less than the best, $\mathrm{MA}$ was epoxidated to ESA, thus the yields of ESA increased with the dosage of $\mathrm{H}_{2} \mathrm{O}_{2}$ increasing. While when the dosage of $\mathrm{H}_{2} \mathrm{O}_{2}$ was higher than the best, adding the dosage would increase the ESA hydrolysis reaction, which would lead to a drop in the yield of ESA. With different catalyst combinations in the same mass, the dosage of $\mathrm{H}_{2} \mathrm{O}_{2}$ for obtaining the maximum yield of ESA could be ranked as follows: $1^{\#}>2^{\#}>3^{\#}$.

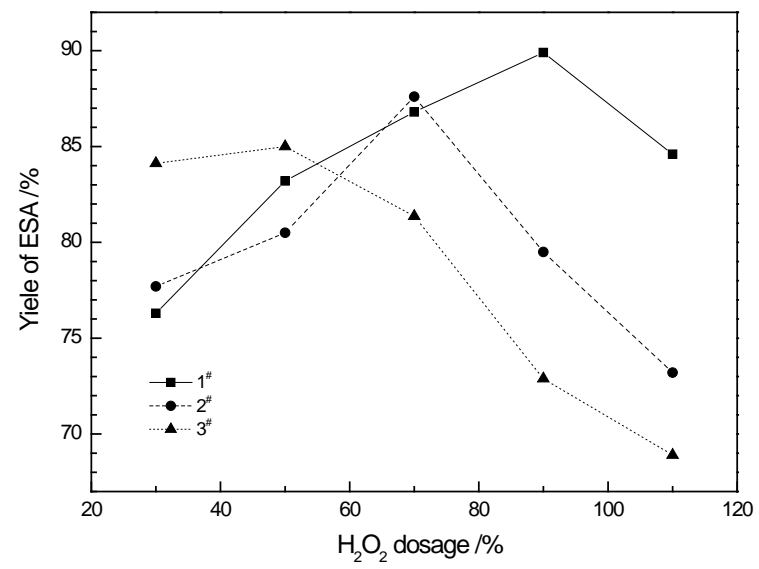

Fig.2. Influence of $\mathrm{H}_{2} \mathrm{O}_{2}$ dosage on the yield of ESA

Effect of epoxidation temperature on the yield of ESA

The synthetic conditions of ESA were as follows: the molar ratio of MA to $\mathrm{NaOH}$ was 1:2, the 
contant of $\mathrm{H}_{2} \mathrm{O}_{2}$ was $50 \%$ (w/w, percentage of MA), the epoxidation time was $2 \mathrm{~h}$, and the contant of the composite catalyst was $2 \%(\mathrm{w} / \mathrm{w})$. Fig. 3 shows the effect of temperature on the yield of ESA with different composit catalysts. While this reaction is a consecutive reaction, the ESA is easily hydrolyzed to tartaric acid in an acid condition. In Fig.1, the yields of ESA increase with temperature increasing between $55-65{ }^{\circ} \mathrm{C}$. This was because the rate of epoxidation reation was accelerated with temperature increasing and was greater than that of ESA hydrolysis. When the temperature is higher than $70{ }^{\circ} \mathrm{C}$, the yields of ESA decrease observably. This was because $\mathrm{H}_{2} \mathrm{O}_{2}$ decomposed at high temperature, which led to the ESA epoxidating rate decreasing, while, at the high temperature range, the hydrolysis rate of ESA increased. Therefore, the maximum yield of ESA was obtained at $65{ }^{\circ} \mathrm{C}$.

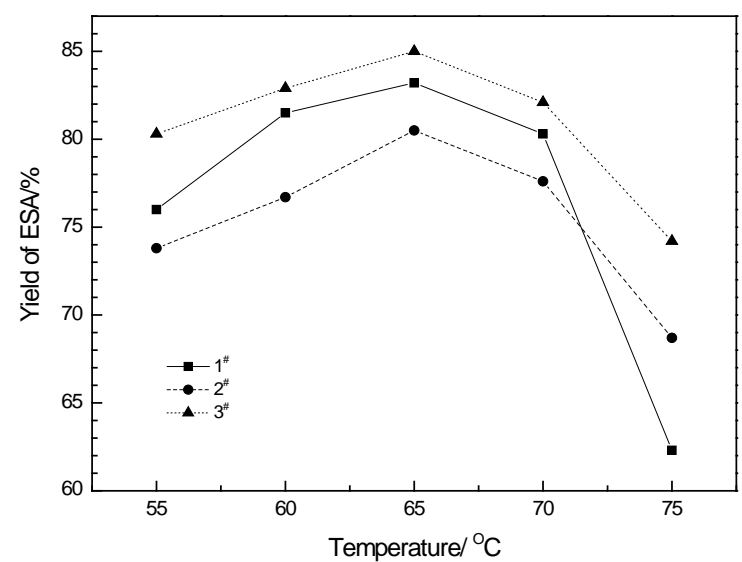

Fig.3. Influence of epoxidation temperature on the yield of ESA

\section{Effect of epoxidation time on the yield of ESA}

The synthetic conditions of ESA were as follows: the molar ratio of MA to $\mathrm{NaOH}$ was 1:2, the contant of $\mathrm{H}_{2} \mathrm{O}_{2}$ were the optimal dosages with different catalysts, respectively, the epoxidation temperature was $65{ }^{\circ} \mathrm{C}$, the contant of the composite catalyst was $2 \%$ (w/w). Fig. 4 shows the effect of epoxidation time on the yield of ESA with different composit catalysts. It costs $1.5 \mathrm{~h}$ to obtain the maximum yield $93.15 \%$ when $1^{\#}$ used as catalyst. It cost $0.5 \mathrm{~h}$ to obtain the maximum yield of 93.27\% with $2^{\#}$ and $92.73 \%$ with $3^{\#}$. It showed that using composite catalysts could save $1 \mathrm{~h}$ comparing with $\mathrm{Na}_{2} \mathrm{WO}_{4}$ as the catalyst for obtaining the maximum yield. For the yield using $\mathrm{Na}_{2} \mathrm{WO}_{4}, \mathrm{Na}_{2} \mathrm{MoO}_{4}$ and $\mathrm{Na}_{3} \mathrm{VO}_{4}$ ternary compound as catalyst was slightly higher than that of $\mathrm{Na}_{2} \mathrm{WO}_{4}$ and $\mathrm{Na}_{2} \mathrm{MoO}_{4}$ dual compound. Considering the price of the catalyst and the practical energy consumption in industrial production, choosing $2^{\#}$ as catalyst is more reasonable. 


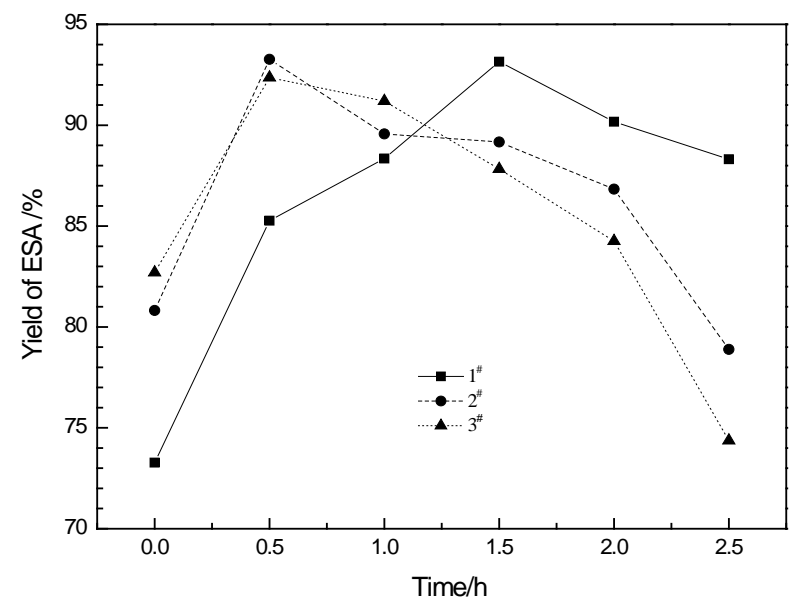

Fig.4. Influence of epoxidation time on the yield of ESA

\section{Purification and IR analysis of ESA}

Putting $\mathrm{HCl}$ into the light yellow solution obtained in the synthetic reaction to adjust $\mathrm{pH}$ to 2, there was a lot of white powder precipitated. Then the powder was filtered and washed by a large amount of ethanol and methanol. The white powder was dried at $60{ }^{\circ} \mathrm{C}$ and the structure was characterized by FT-IR. The strong peak at $3520 \mathrm{~cm}^{-1}$ in Fig. 5 aroses from the deformation vibration of $\mathrm{O}-\mathrm{H}$ bond bending in $-\mathrm{COOH}$, the absorption peak at 3037 $\mathrm{cm}^{-1}$ is attributed to the $\mathrm{C}-\mathrm{H}$ stretching in epoxy group, the absorption peak at $1636 \mathrm{~cm}^{-1}$ is $\mathrm{C}=\mathrm{O}$ stretching in $-\mathrm{COOH}$, the peak at $1456 \mathrm{~cm}^{-1}$ is $\mathrm{C}-\mathrm{H}$ deformation vibration peak of epoxy group, the peaks at $1270 \mathrm{~cm}^{-1}$ and $1068 \mathrm{~cm}^{-1}$ are C-O stretching in $-\mathrm{COOH}$, and the peaks at $1134 \mathrm{~cm}^{-1}$ and 951 $\mathrm{cm}^{-1}$ are the vibration absorption peak of epoxy group, which indicate that the product was ESA.

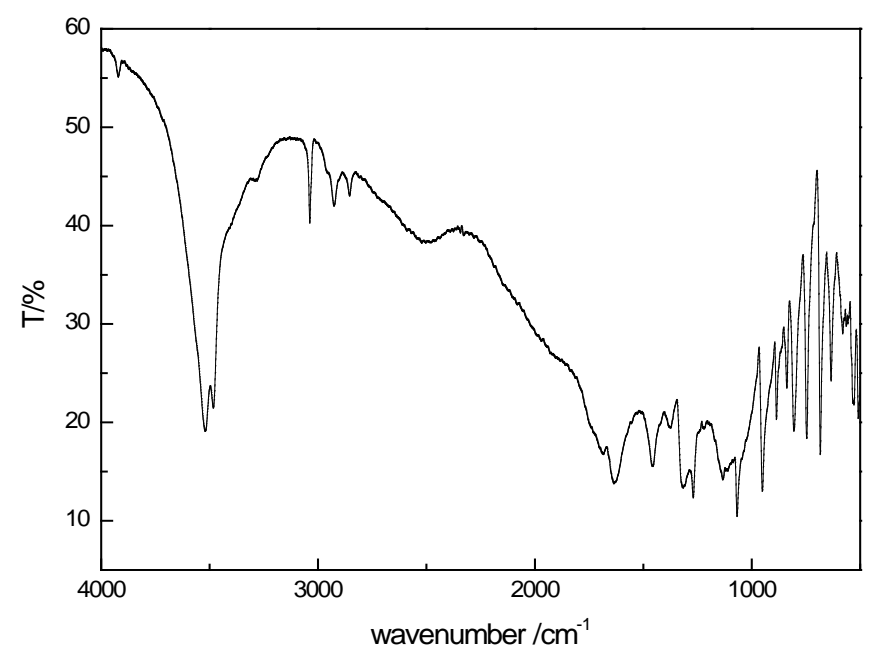

Fig.5. IR spectrum of ESA

\section{Conclusions}

ESA was successfully synthesized using MA as raw material. The optimum conditions for the synthesis of ESA were as follows: the molar ratio of MA to $\mathrm{NaOH}$ was 1 :2, the contant of $\mathrm{H}_{2} \mathrm{O}_{2}$ was $70 \%(\mathrm{w} / \mathrm{w})$, the epoxidation temperature was $65{ }^{\circ} \mathrm{C}$, the epoxidation time was $0.5 \mathrm{~h}$, the mass ratio of $\mathrm{Na}_{2} \mathrm{WO}_{4}$ to $\mathrm{Na}_{2} \mathrm{MoO}_{4}$ was $1: 1$, and the contant of the composite catalyst was $2.5 \%(\mathrm{w} / \mathrm{w})$. 


\section{Acknowledgement}

In this paper, the research was sponsored by the National Natural Science Foundation of China (21376062) and and the Natural Science Foundation of Hebei Province (E2013302037 and B2015302008).

\section{References}

[1] Kesser, Stephen M. Method of inhibiting in aqueous systems:US 5256332[P],1993.

[2] Pardue J E. A new inhibitor for scale sequence applications:SPE 26023[P],1991.

[3] Baofeng Liang, Yue Yang. Synthesis of epoxysuccinic acid and poly epoxysuccinic acid[J]. Petrochemical Technology \& Application, 2008, 26(1): 39-43.

[4] Yonghong Sun, Wenhua Xiang, Ying Wang. Study on polyepoxysuccinic acid reverse osmosis scale inhibitor[J]. Journal of Environmental Sciences, 2009, 21: 73-75.

[5] Dan Liu, Wenbo Dong, Fengting Li, Comparative performance of polyepoxysuccinic acid and polyaspartic acid on scaling inhibition by static and rapid controlled precipitation methods[J]. Desalination, 2012, 304: 1-10.

[6] Huixia Feng, Ting Zhang, Yi Wang, Xia Zhao. Study on synthesis of polyepoxysuccinic acid through one step method[J]. Modern Chemical Industry, 2006, 26 (2): 331-334.

[7] Zhifang Lv, Wei Dong, Mingzhu Xia, Wu Lei, Fengyun Wang. Synthesis of epoxysuccinic acid[J]. Speciality Petrochemicals, 2001, (5): 7-9.

[8] Huijuan Qian, Yican Wang, Liwu Song, Jietang Zhao, Chengfeng Ren, Qinghe Gao. Synthesis of epoxysuccinic acid with tungstate catalyst[J]. Technology \& Development of Chemical Industry, 2014, 43(1): 9-12.

[9] Meiling Wu, Xia Li, Huaizhi Wu, Jianguang Qin, Senmao Li. Determination of epoxysuccinic acid(salt)[J]. Chemical Research and Application, 2012, 24 (7): 1087-1090. 